\title{
Do DM professionals need to update their competencies to respond to older workers?
}

\author{
Wolfgang Zimmerman \\ Pacific Coast University for Workplace Health Sciences, Port Alberni V9Y 0A7, Canada. wolfgang@nidmar.ca
}

Background: The proportion of people with disabilities in the 50 to 64 year age is double that of those aged 35 and 44 years. Economic inactivity rates are almost 40\% higher. Disability Management (DM) professionals are in the front line in responding to these challenges.

Objectives: A key issue is the nature and extent that new knowledge and additional skills are required to respond effectively to the needs of older workers. Methods In 2013, the National Institute of Disability Management and Research (NIDMAR), in collaboration with Pacific Coast University for Workplace Health Sciences, brought stakeholders, professionals and researchers together to explore a more integrated approach to older workers. A follow up questionnaire was distributed to participants in order to validate the conclusions.

Findings: The consensus was that DM professionals already had the skills required but that there were a number of areas where it was essential that knowledge be enhanced and attitudes changed. DM professionals required better knowledge of age-related health conditions, the complexities of co-morbidity and human rights issues and to acknowledge longer recovery times, the health benefits of work, the ability to learn new skills and older workers' added value to teams.

Discussion: In addition to the essential competences, 22 desirable domains of knowledge, skill and attitude were identified. The taxonomy produced has the potential to form the basis of a training needs analysis (TNA) that could be used by organizations to evaluate the competences of DM professionals and to produce age-sensitive continuing professional development modules.

Conclusion: DM professionals are equipped with the necessary skills to respond effectively to older workers. The appropriate application of these skills requires a change in attitudes and a deeper knowledge of age-related health conditions and the human rights implications of the intersectionality of age and disability at work. 